\title{
AN ANALYSIS OF INTENTION TO DO ECOTOURISM IN THE NEW NORM: A COMPARATIVE STRUCTURAL MODEL BETWEEN MALAYSIA AND INDONESIA
}

\author{
Yuary Farradia ${ }^{1}$, Hari Muharam ${ }^{2} \&$ Salmah Azzubaidi ${ }^{3}$ \\ ${ }^{1}$ Faculty of Business Economics and Social Development, Universiti Malaysia Terengganu \\ ${ }^{2,3}$ Faculty of Economics and Business Universitas Pakuan, Bogor Indonesia \\ (yuary.farradia@umt.edu.my, hari.muharam@unpak.ac.id, salmahazzubaidi@gmail.com)
}

\begin{abstract}
Tourism contributes to the growth of economy of a nation through employment, the multiplier effect, and foreign exchange earnings. It also contributes towards a positive balance of payments. Eco-tourism is the natural evolution of tourism that cares for the environment, culture and local traditions, while promoting environmental education. The coronavirus (COVID-19) pandemic has had a significant negative effect on the tourism industry in almost all countries in Asia including Malaysia and Indonesia, therefore an analysis of the intention to undertake eco-tourism in the new norm of the post pandemic period is the basis for consideration of this research paper in a bid to turnaround the tourism industry.
\end{abstract}

KEYWORDS: Ecotourism Intention, Covid - 19, Awareness of consequences, Personal norms, Social norms

\section{PURPOSE AND BACKGROUND}

The COVID-19 lockdown around the world has had a negative impact on the world economy and has adversely affected the tourism industry. Ecotourism is one of the options that the tourism sector and travelers may consider as a means to minimise the need for social distancing that are part of the pandemic prevention safeguards. The people who implement and participate in eco-tourism activities should follow the principles of eco-tourism such as minimising physical, social, behavioral and psychological impacts.

A study by Romero et al. (2019) found that the intention to practice eco-tourism in Chile and Spain were influenced by awareness of consequences, personal norms, and social norms and they recommended further study in other countries. With regards to this from an ecotourism perspective, there is a need to understand the behaviour of eco-tourists.

The eco-tourist's behaviour is an area of opportunity for research in order to understand factors, whether economic, cultural, social, demographic, or psychographic, that determine this behaviour. This research uses the value-belief-norm (VBN) theory and the theory of planned behaviour (TPB) to analyse the intention to practice ecotourism among eco-tourists from two countries.

An earlier study by Stern et al. (1999) recommended the VBN model as a comprehensive model that uses a psychological approach. In addition, a study by Choi et al. (2015), used the VBN model in tourism to examine consumption in eco-friendly hotels.

The objective of this study is to create a new model that facilitates an understanding of the intention to practice ecotourism as a means to turn the industry around in the new norms of the COVID-19 pandemic which still have various unpredictable circumstances. 
This research is also aimed at understanding the determiners in the process of a consumer's intention in ecotourism context, as well as verifies the growing importance of ecotourism. Therefore, it can be said that this comparative research is to analyze the intention to practice ecotourism among eco-tourists from the two countries by comparing eco-tourists in Malaysia and Indonesia, where the emphasis on ecotourism as a part of the economy is similar.

\section{METHODOLOGY}

A quantitative study on the tourism industry with individuals as the unit analysis based on convenience sampling method. 200 eco-tourists were chosen as respondents from both Malaysia and Indonesia and they were given five-point Likert scale questionnaire which was analysed using multi group analysis (MGA) smart PLS 3. MGA is one of the most efficient ways to assess moderation across multiple relationships (Hair et al., 2017). Construct variables are intention to do ecotourism, awareness of consequences, personal norms and social norms. Moderator variable is Covid-19.

\section{FINDINGS}

In general, there is a significant and positive relationship between COVID-19 and the intention to engage in Ecotourism. Personal norms and social norms have a positive relationship with the intention to engage in Ecotourism. However, there is no moderating effect from the COVID- 19 pandemic on the intention to engage in Ecotourism.

In Indonesia, there is a significant and positive relationship between COVID-19 and the intent to engage in Ecotourism. Personal norms have a significant positive relationship on the intention to engage in Eco-tourism. There is no moderating effect of the COVID - 19 pandemic on the on intention to engage in Ecotourism.

In Malaysia, there is a significant and positive relationship between Covid-19 and the intention to do Ecotourism. Awareness of consequences has significant positive relationship with the intention to engage in Ecotourism. There is no moderating effect from the COVID-19 pandemic on the intention to engage in Ecotourism.

\section{CONCLUSION}

This study analyses the intention to engage in ecotourism using multi group analysis to compare the business models used in Malaysia and Indonesia. The findings demonstrate different significant factors affect the intention to engage in ecotourism. The awareness of consequences and the COVID -19 pandemic has a positive relationship with the intention to engage in ecotourism in Malaysia, while in Indonesia, personal norms and the pandemic have a positive relationship with the intention to engage in Eco-tourism.

Nevertheless, the COVID-19 pandemic has no role in moderating the results of this research paper. A combined analysis with the results from both countries demonstrate that both personal and social norms have a positive relationship on the intention to engage in ecotourism. 


\section{CONTRIBUTION/PRACTICAL IMPLICATIONS}

The results recommend ecotourism as a means for the country to recover from the current economic downturn due to the COVID-19 pandemic. There is a need to test the model in particular with regard to the potential eco-tourism areas within the two countries.

\section{ACKNOWLEDGEMENTS}

Thank you for the support of the Universiti Malaysia Terengganu. Thank you for the collaboration with the Universitas Pakuan, Bogor Indonesia for finding the respondents in Indonesia.

\section{REFERENCES}

Hair, J. F., Hult, G. T. M., Ringle, C. M., \& Sarstedt, M. (2017b). A primer on Partial Least Squares Structural Equation Modeling (PLS-SEM) (2nd ed.). Thousand Oaks: Sage Publication.

Lorenzo-Romero, C., M.-D.-C. Alarcón-del-Amo, \& J.-A. Crespo-Jareño. (2019). Cross-cultural analysis of the ecological behavior of Chilean and Spanish ecotourists: A structural model. Ecology and Society, 24(4), 38. https://doi.org/10.5751/ES-11343-240438

Stern, P. C., T. Dietz, T. Abel, G. A. Guagnano, \& L. Kalof. (1999). A value-belief-norm theory of support for social movements: The case of environmentalism. Human Ecology Review, 6, 81-97. 